\title{
Development of The Conception of Mechanical Energy Conservation with Interactive Lecture Demonstration Method using Simple Experiments for Grade 7 Students
}

\author{
Willi Anindita Wijanarka ${ }^{1}$, Julius Zai ${ }^{1}$, Winda Noor Santi ${ }^{1}$, Laifa Rahmawati ${ }^{2}$, and Mohd \\ Rustam Bin Mohd Rameli ${ }^{3}$ \\ ${ }^{1}$ Program Studi Magister Pendidikan Fisika, Universitas Ahmad Dahlan. \\ ${ }^{2}$ Program Studi Pendidikan Fisika, Universitas Ahmad Dahlan. \\ ${ }^{3}$ Fakulty of Education, Universiti Teknologi Malaysia \\ ${ }^{1}$ Jl. Pramuka No.42, Pandeyan, Umbulharjo, Yogyakarta, Indonesia. \\ ${ }^{2}$ Jl. Ring Road Selatan, Tamanan, Banguntapan, Bantul Yogyakarta, Indonesia. \\ ${ }^{3}$ Johor Bahru, Johor Darul Takzim, Malaysia \\ Email: *willy.anindito@yahoo.com
}

\begin{abstract}
The purpose of this research is to develop a student's conception of mechanical energy conservation with the Interactive Lecture Demonstration method. The participants consisted of 19 students of class 7E SMP Muhammadiyah 1 Mlati in 2018/2019 academic year. The analysis of the student's sheet prediction showed that most students do not understand the conception of mechanical energy conservation. After learning applied, it is known that all students have understood the influence of the height of the object on potential energy, 18 of them have understood the influence of the mass of the object on potential energy. While students' understanding of changes in mechanical energy when objects fall and the influence of mass on kinetic energy has increased slightly. Through the Wilcoxon signed-rank test, it was concluded that there was an effect of the use of interactive demonstration methods on student learning outcomes in the matter of mechanical energy conservation conceptions.
\end{abstract}

Keywords: mechanical energy conservation, interactive lecture demonstration

\section{Introduction}

Mastery of conceptions of physics necessary for students to solve problems of physics with the correct approach. Referring to the studies in the field of physical education found that there are differences in approach to problem-solving among students who are proficient with the less adept. A proficient student uses problem-solving strategies based on the relevant concept, while students who are less proficient based on shallow surface concept [1]. Their less proficient students were caused from the beginning is not applied learning models that reinforce mastery of conceptions. Students with a weak conception will certainly be a problem in learning.

In learning activities, the teacher gives exercises that usually a quantitative question to students with hope through the question, students can master the conception well. Whereas based on studies conducted proved that the quantitative problem solving does not help students to understand the conceptions in depth [2]-[5]. Researchers in the field of physical education also agreed that learning only rely on lecture and traditional learning methods do not successfully repair the misconceptions of the majority of students [6]. One of the conceptions of physics that are often misunderstood by the students is the conception of mechanical energy conservation. Many students do not understand that mechanical energy conservation involves changes to a form of mechanical energy into other forms of mechanical energy with the energy that neither increased nor diminished. Then a learning method is needed to correct the student's misconception. Learning models that considered can encourage student involvement and correct misconceptions in physics are the Interactive Lecture Demonstration (ILD) [7]. 
Wijanarka et al.

The researchers examined the effect of ILD in learning, including for the development of energy conservation concepts for 10th-grade students [6]. Through this research, it is known that the use of ILD promoted students' understanding of the concept and improved their reasoning skills. The combination of traditional learning with a small portion of ILD activity has been shown to produce significant NGain values [8], [9]. The ILD activity promotes effectively the conceptual understanding of momentum, the conceptual change achieved from predictions to results after observation and discussion are around $70 \%-80 \%$ [10]. ILD can make a difference in students' conceptual understanding as well as their experiences, demonstrating the potential value-add that can be provided by investing in active learning to enhance lectures [11].

The design of experiments in this study is dropping eggs with a variety of sizes and heights to develop students' conception of mechanical energy conservation. Research conducted aimed at obtaining information about initial students' mastery of the conceptions of mechanical energy conservation and the effectiveness of the Interactive Lecture Demonstration model to correct student misconceptions about the conception of mechanical energy conservation.

The application of the Interactive Lecture demonstration method in this study began with students expressing their predictions of the state of the egg after being dropped, the prediction is poured in the form of drawing. The use of drawing is meant to attract attention, excite, and facilitate communication that is hard to imagine the students about the conception of mechanical energy conservation. The use of pictures is worth as alternative learning to improving learning outcomes because learning physics with pictures makes the student more eager to follow lessons [12].

\section{Theory}

\section{Interactive Learning Demonstration (ILD) Method in Physics Learning}

Physics is a branch of Natural Sciences so Physics can be seen as a process, procedure, and product. As a process, Physics is a scientific activity to find new knowledge or perfect existing knowledge. As a procedure, Physics is a methodology for knowing something (generally in the form of research) that is commonly called the scientific method. As a product, Physics is the result of a process, which is in the form of knowledge being taught or in the form of a knowledge book.
Development of The Conception of Mechanical Energy Conservation with Interactive Lecture Demonstration...

Physics is born and developed through observation, formulating problems, making hypotheses, conducting experiments to test hypotheses, and drawing conclusions. Therefore Physics learning should use an inquiry approach that involves students' ability to search and investigate systematically, logically, critically, and analytically to the fullest. This will ultimately make students able to formulate their findings with confidence [13]. One method based on an inquiry approach is an Interactive Lecture Demonstration method.

The ILD is one of the student-centered constructive learning so that students think actively of their conceptions and enable students to build their understanding about main concept through demonstrations and discussion with colleagues [8]. Learning in ILD through teacher demonstration about a science experiment that lasted interactive with the students for their predictions from students about how something (the experiment) happened. In the ILD, students engage in activities that test the validity of the initial understanding of the conception. This model can be applied in large and small class sizes. ILD learning consists of three stages:

1. Predict the outcome of the demonstration will be done. The first students predict individually and then explain to other students about the most likely outcomes obtained from the demonstration.

2. Experience the demonstration. Students conduct experiments in small groups, students conduct a survey or process data to test the truth of their predictions.

3. Reflecting on the experimental results. Students think about the causes of the experimental results in suitable with or not suitable for their predictions.

ILD is included in the active learning method in which students build their knowledge independently through observation activities. In this method the learning cycle is used, where students confront their initial belief with the results of observations. When the results of observations conflict with the students' initial beliefs, students will change their beliefs. In this learning method, the teacher acts as a guide for learning, not transferring knowledge. Discussion and collaboration among fellow students is an important part of the ILD method. The role of experiments in this method is not to confirm the knowledge that has been obtained in the classroom, but rather as a basic conception construct.

The Interactive Demonstration Method has advantages, including:

1. It does not require a lot of tools and materials and is easy to implement. 
Wijanarka et al.

2. Make learning activities more interesting.

3. Student can compare theory with reality directly.

4. Learning departs from the students' initial ideas.

The Interactive Lecture Demonstration Method has several weaknesses, including not all objects or physical phenomena than can be demonstrated and demonstrations are difficult to understand if done by a teacher who lacks mastery of the topic.

\section{Methodology}

The instrument used to measure students' understanding are pretest, posttest, and student prediction sheet. Pretest and posttest contain four questions that measure students' understanding of mechanical energy coservation. In the prediction sheet, students predict the condition of the egg after hitting the floor, as a result, dropped from a certain height, the prediction is expressed in the form of drawing. Pretest and prediction sheet worked by students before learning begins while the posttest did after going through the learning process.

Analysis of prediction sheet performed by first categorizing the level of damage to the eggs in the students drawing. Furthermore, to determine the initial understanding of the students about the conception of mechanical energy conservation by comparing the level of damage to the eggs in each experiment. By comparing the level of damage to the eggs in the experiment one and two will be obtained information about the students' initial understanding of the conception of the object's mass effect on its mechanical energy. While comparing the level of damage to the eggs in experiment two, three and four will be obtained information about students' initial understanding of the conception of the effects of height on the object of its mechanical energy. The posttest and pretest values were analyzed to determine the effectiveness of learning through normalized gain or $\mathrm{N}$-gain $(<g>)$ which satisfies the equation (1).

$$
\langle g\rangle=\frac{\text { posttest }- \text { pretest }}{100-\text { pretest }}
$$

with normalized gain ( $\mathrm{N}$-gain) criterion that can be seen in Table 1 [14].

Furthermore, the Wilcoxon signed rank test was used to test the hypothesis proposed in the study $(\mathrm{Ha})$ $=$ "there is a difference between pretest to posttest learning outcomes, which means there is the effect of the use of methods of Interactive Lecture
Development of The Conception of Mechanical Energy Conservation with Interactive Lecture Demonstration...

Demonstrations to 7th grade student learning outcomes in the conception of mechanical energy conservation". If the Wilcoxon signed rank test results demonstrate the value of Asymp. Sig. (2tailed) $<0.05$ so $\mathrm{Ha}$ is received, if Asymp. Sig. (2tailed) $>0.05$, Ha rejected.

Table 1. Normalized Gain Criteria

\begin{tabular}{cc}
\hline N-gain $(<\boldsymbol{g}>)$ & Criteria \\
\hline$(<g>) \geq 0,7$ & High \\
$0,3 \leq(<g>)<0,7$ & Moderate \\
$(<g>)<0,3$ & Low \\
\hline
\end{tabular}

\section{Tools and materials}

Tool and materials required are:

1. One small-sized eggs (quail egg) and 3 largesized eggs (broilers egg)

2. Measuring tape

3. digital Balance

4. One piece $\mathrm{A} 3$ size paper, 1 piece $2 \mathrm{xA} 3$ paper, and 2 piece $4 \mathrm{xA} 3$ paper

\section{ILD scenario}

Students predict the outcome of the four demonstration experiments that will be conducted by the teacher, the prediction expressed in the form of a drawing of egg condition after hitting the floor. Four demonstration experiments are:

Experiment 1: small egg dropped from a height of 1 meter.

Experiment 2: large egg dropped from a height of 1 meter.

Experiment 3: large egg dropped from a height of 2 meters.

Experiment 4: large egg dropped from a height of 3 meters.

Students conduct experiments 1 to 4 then record the results for comparison with predictions. Note the experiment result consists of egg drawing after hitting the floor, the farthest distance of the traces fallen eggs from the point of impact, and a description of the level of egg damage. The farthest distance and the description of the level of egg damage used by the student to infer the relationship between mass and height of falling eggs with mechanical energy. 
Wijanarka et al.

\section{Results and Discussion}

\section{Students Prediction Sheet}

The students' predictions of damage level of eggs for each experiment as follows in Table 2 until Table 5.

Table 2. Kinds of predictions with the number and percentage of answers for experiment 1

\begin{tabular}{|c|c|c|c|c|}
\hline \multicolumn{3}{|c|}{ The condition of the egg } & \multirow{2}{*}{$\begin{array}{c}\text { Total } \\
\text { answers }\end{array}$} & \multirow{2}{*}{$\begin{array}{c}\text { Percentage } \\
\text { of responses } \\
(\%)\end{array}$} \\
\hline Yolk & $\begin{array}{l}\text { Egg } \\
\text { white }\end{array}$ & Egg shell & & \\
\hline intact & intact & cracking & 1 & 5.26 \\
\hline intact & intact & ruptured & 12 & 63.16 \\
\hline intact & intact & $\begin{array}{l}\text { severe } \\
\text { rupture }\end{array}$ & 1 & 5.26 \\
\hline intact & ruptured & ruptured & 3 & 15.79 \\
\hline intact & ruptured & $\begin{array}{c}\text { severe } \\
\text { rupture }\end{array}$ & 1 & 5.26 \\
\hline ruptured & intact & ruptured & 1 & 5.26 \\
\hline
\end{tabular}

Table 3. Kinds of predictions with the number and percentage of answers for exper iment 2

\begin{tabular}{|c|c|c|c|c|}
\hline \multicolumn{3}{|c|}{ The condition of the egg } & \multirow{2}{*}{$\begin{array}{c}\text { Total } \\
\text { answers }\end{array}$} & \multirow{2}{*}{$\begin{array}{l}\text { Percentage of } \\
\text { responses } \\
(\%)\end{array}$} \\
\hline Yolk & Egg white & Egg shell & & \\
\hline intact & intact & cracking & 1 & 5,26 \\
\hline intact & intact & ruptured & 8 & 42,11 \\
\hline intact & intact & $\begin{array}{l}\text { severe } \\
\text { rupture }\end{array}$ & 4 & 21,05 \\
\hline intact & ruptured & ruptured & 2 & 10,53 \\
\hline intact & ruptured & $\begin{array}{l}\text { severe } \\
\text { rupture }\end{array}$ & 1 & 5,26 \\
\hline ruptured & intact & $\begin{array}{l}\text { severe } \\
\text { rupture }\end{array}$ & 2 & 10,53 \\
\hline ruptured & ruptured & ruptured & 1 & 5,26 \\
\hline
\end{tabular}

Table 4. Kinds of predictions with the number and percentage of answers for experiment 3

\begin{tabular}{|c|c|c|c|c|}
\hline \multicolumn{3}{|c|}{ The condition of the egg } & \multirow{2}{*}{$\begin{array}{c}\text { Total } \\
\text { answers }\end{array}$} & \multirow{2}{*}{$\begin{array}{l}\text { Percentage of } \\
\text { responses }(\%)\end{array}$} \\
\hline Yolk & Egg white & Egg shell & & \\
\hline intact & intact & ruptured & 3 & 15,79 \\
\hline intact & intact & $\begin{array}{c}\text { severe } \\
\text { rupture }\end{array}$ & 6 & 31,58 \\
\hline intact & ruptured & ruptured & 5 & 26,32 \\
\hline intact & ruptured & $\begin{array}{l}\text { severe } \\
\text { rupture }\end{array}$ & 1 & 5,26 \\
\hline ruptured & intact & $\begin{array}{l}\text { severe } \\
\text { rupture }\end{array}$ & 1 & 5,26 \\
\hline ruptured & ruptured & $\begin{array}{l}\text { severe } \\
\text { rupture }\end{array}$ & 3 & 15,79 \\
\hline
\end{tabular}

Development of The Conception of Mechanical Energy Conservation with Interactive Lecture Demonstration...

Indicators that students understand the conception of the object mass influence on the mechanical energy is if the damage of the egg described in experiment two more severe than experiment one. After a comparison of the level of egg damage between experiments one and two, it is known that $58 \%$ of students do not understand the conception of the effect of object mass on mechanical energy. Students' misconceptions can be seen in the absence of picture that show an increase in egg damage in experiments one to two. Students assume that the mass of objects does not affect the amount of mechanical energy generated. Students are not able to associate that egg with larger mass at a certain height has larger mechanical energy in the form of potential energy, which when egg dropped, the potential energy gradually turns into another mechanical energy called kinetic energy which results in more severe damage to the eggshell, yolk, and egg white.

Table 5. Kinds of predictions with the number and percentage of answers for experiment 4

\begin{tabular}{|c|c|c|c|c|}
\hline \multicolumn{3}{|c|}{ The condition of the egg } & \multirow{2}{*}{$\begin{array}{c}\text { Total } \\
\text { answers }\end{array}$} & \multirow{2}{*}{$\begin{array}{l}\text { Percentage of } \\
\text { responses }(\%)\end{array}$} \\
\hline Yolk & Egg white & Egg shell & & \\
\hline Intact & intact & Cracking & 1 & 5,26 \\
\hline Intact & intact & Ruptured & 2 & 10,53 \\
\hline Intact & intact & $\begin{array}{l}\text { severe } \\
\text { rupture }\end{array}$ & 4 & 21,05 \\
\hline Intact & ruptured & Ruptured & 4 & 21,05 \\
\hline Intact & ruptured & $\begin{array}{l}\text { severe } \\
\text { rupture }\end{array}$ & 4 & 21,05 \\
\hline ruptured & ruptured & Ruptured & 1 & 5,26 \\
\hline ruptured & ruptured & $\begin{array}{l}\text { severe } \\
\text { rupture }\end{array}$ & 3 & 15,79 \\
\hline
\end{tabular}

Indicators that students understand the conception of the object heights influence on the mechanical energy is if the damage of the egg described successively increased from experiment two to four. After a comparison between experiments 2, 3, and 4 is known that $63 \%$ of students do not understand the conception about the effects of height on mechanical energy. Students' misconceptions can be seen in the absence of pictures that show the gradual increase in damage of eggs dropped in experiment 2.3, then 4 . Students assume the height of the object does not affect the mechanical energy. Students are not able to associate that eggs at higher positions have larger mechanical energy in the form of potential energy, which when egg dropped, the potential energy gradually changes into another form of mechanical energy called kinetic energy which causes more severe damage to the eggshell, yolk, and egg whites. 
Wijanarka et al.

\section{Results of Students Experiment}

Students draw the shape of the eggs after hitting the floor on a sheet of student experimental results, while teachers take the egg photos, photos are shown in the Figure 1.

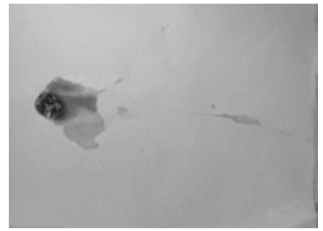

(a)

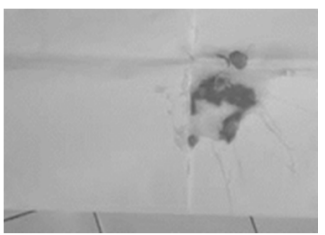

(c)

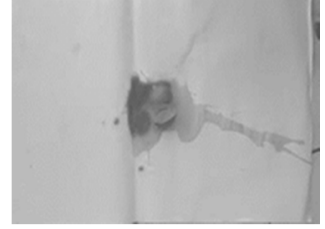

(b)

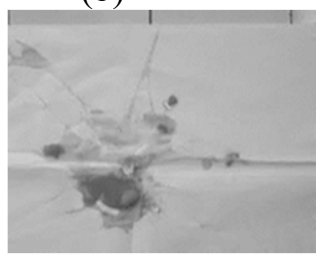

(d)
Figure 1. Photo of egg shape after hitting the floor:

(a) Experiment 1, (b) Experiment 2, (c) Experiment 3, and (d) Experiment 4

It can be seen in the photo that the level of egg damage gradually increased from experiment one to the four. Farthest distance data and description of the level of eggs damage is written on the Students Worksheet (LKPD) are presented in the following table:

Table 6. Farthest distance of the trail egg outbreaks from the point of impact

\begin{tabular}{clccc}
\hline Exp & $\begin{array}{l}\text { Egg Type } \\
\text { (Egg Size) }\end{array}$ & Mass & Height & $\begin{array}{c}\text { The farthest } \\
\text { distance of the } \\
\text { trail eggs } \\
\text { outbreak from } \\
\text { the point of } \\
\text { impact }\end{array}$ \\
\hline 1 & $\begin{array}{l}\text { Quail egg } \\
\text { (Small) }\end{array}$ & $10 \mathrm{~g}$ & $1 \mathrm{~m}$ & $23 \mathrm{~cm}$ \\
\hline 2 & $\begin{array}{l}\text { Broilers } \\
\text { egg (Large) }\end{array}$ & $50 \mathrm{~g}$ & $1 \mathrm{~m}$ & $25 \mathrm{~cm}$ \\
\hline $\begin{array}{l}\text { Broilers } \\
\text { egg (Large) } \\
\text { Broilers } \\
\text { egg (Large) }\end{array}$ & $50 \mathrm{~g}$ & $2 \mathrm{~m}$ & $127 \mathrm{~cm}$ \\
\hline
\end{tabular}

The difference between experiments one and two is the egg mass dropped. The egg mass in experiments 2 is greater than experiments 1 . By comparing the farthest distance of the trail egg outbreaks from the point of impact and level of egg damage between experiments one and two, students find that the farthest distance of the trail egg outbreaks from the
Development of The Conception of Mechanical Energy Conservation with Interactive Lecture Demonstration...

point of impact and the level of egg damage in experiments 2 exceeded experiment 1. That reinforces by comparing drawing of the shape of the egg after hitting the floor between experiments 1 and 2 on a sheet of student experimental results. Then students concluded that the greater the mass of the object causes the greater the mechanical energy generated.

Tabel 7. Damage level of the egg

\begin{tabular}{clll}
\hline \multirow{2}{*}{ Exp } & \multicolumn{3}{c}{ The level of damage to the eggs } \\
\cline { 2 - 4 } & eggshell & Egg whites & Egg yolk \\
\hline 1 & Cracked & Splattered & Intact \\
2 & Split into two & Splattered & Splattered \\
3 & $\begin{array}{l}\text { Broken into } \\
\text { pieces }\end{array}$ & Splattered & Splattered \\
4 & $\begin{array}{l}\text { Broken into } \\
\text { pieces }\end{array}$ & Splattered & Splattered \\
\hline
\end{tabular}

The difference between experiments 2, 3 and 4 is the height of the egg dropped. Egg height successively increases from experiment 2 to 4 . Through comparison of experiments 2, 3, and 4, students know that the farthest distance of the trail eggs outbreaks from the point of impact and the level of egg damage in experiments 3 exceeds experiment 2. Students also know that the farthest distance of the trail eggs outbreaks from the point of impact in experiment 4 exceeds experiment 3 . That reinforces by comparing drawing of the shape of the egg after hitting the floor between experiments 2,3 , and 4 on a sheet of student experimental results. Then students concluded that the greater the height of the object causes the greater the mechanical energy generated.

\section{Pretest and Posttest}

The pretest and posttest consisted of four questions that measured the mastery of conceptions about the conservation of mechanical energy. The number 1 pretest and posttest questions test students' understanding of the effect of object height on potential energy. Question number 2 examines students' understanding of the effect of object mass on their potential energy. Question number 3 examines students' understanding of the effect of object mass on their kinetic energy. While question number 4 tests students' understanding of changes in the shape of mechanical energy in the case of mechanical energy conservation on a falling object. The average score of the pretest and posttest was 33.55 and 67.11 respectively. $\mathrm{N}$-gain obtained is in 
Wijanarka et al.

the medium category which is equal to 0.50 . N-gain calculations are also performed on each number whose results are presented in the Table 8 .

Table 8. N-gain table for each number

\begin{tabular}{cccc}
\hline No. & $\begin{array}{c}\text { pretest average } \\
\text { score }\end{array}$ & $\begin{array}{c}\text { posttest } \\
\text { average score }\end{array}$ & N-Gain \\
\hline 1 & 63,2 & 100 & 1,00 \\
2 & 26 & 95 & 0,93 \\
3 & 32 & 42,1 & 0,15 \\
4 & 13 & 31,6 & 0,21 \\
\hline
\end{tabular}

Furthermore, the normality test. The test sample amounted to 19 which means that on a group 50 then do the Shapiro-Wilk normality test. Probability studies were selected for 0.05 so that the number of 19 samples obtained Wilk table at 0.9010. Based on the calculation of the Shapiro-Wilk normality test, Wilk obtained count on the results of pretest and posttest respectively 0.94 and 0.79 . Wilk calculated from the results of the pretest is greater than the Wilk table, so the hypothesis is accepted which means the pretest data is normally distributed. Whereas Wilk counts from the posttest results smaller than Wilk tables, so the hypothesis is rejected which means the posttest results data are not normally distributed.

If there are data that are not normally distributed, the t-test cannot be applied, so that an alternative test is carried out, namely the Wilcoxon signed-rank test to determine the significance of the use of interactive demonstration methods to improve student learning outcomes. From the results of the Wilcoxon signedrank test with a research critical limit of 0.05 , the Asymp. Sig value was obtained. (2-tailed) $=0.0005$. Because of the value Asymp.Sig. (2-tailed) is smaller than the critical threshold of research so $\mathrm{Ha}$ is received. Based on these results concluded that there is a difference between pretest to posttest learning outcomes, which means there is the effect of the use of methods of Interactive Lecture Demonstrations to 7th-grade student learning outcomes in the conception of mechanical energy conservation.

Based on the achievement of $\mathrm{N}$-gain at number one and two, it was concluded that the learning carried out was very effective in increasing the mastery of students' conceptions of the influence of height and mass of objects on their potential energy. All students were able to understand the effect of height on mechanical energy. This can be seen in the answer of the number 1 posttest question which shows that all students have been able to sort objects that have potential energy from the smallest to the largest based on object height. Based on the answers of the number
Development of The Conception of Mechanical Energy Conservation with Interactive Lecture Demonstration...

2 of the posttest question, it is known that 18 students have been able to understand the influence of mass on the potential energy. This can be seen in the answers of the number 2 in posttest question which shows that 18 students have been able to sort the objects that have potential energy from the smallest to the largest based on object mass. This is because the students see the demonstration directly and do their experiments, and the experimental results reviewed by students that make learning more meaningful for students. Assessment of students to the egg drawing after hitting the floor reinforces the conception of the student because the drawing will be meaningful in learning when analyzed or assessed conceptions, relationships between conceptions, and other matters contained in the drawing [15].

It appears that the $\mathrm{N}$-gain for number 3 and 4 is low but still indicate that student understanding of the effect of object mass on kinetic energy and changes in the form of mechanical energy in falling objects has increased. Based on students' answers to the number 4 posttest question, it is known that after learning, the majority of students still unable to understand that objects with a certain mass when falling will experience the changing in mechanical energy from potential energy into other forms of mechanical energy, called kinetic energy. Then based on the student's answer of the number 3 posttest, it is known that the majority of students unable to understand that the mass of an object is directly proportional to the kinetic energy so that when hitting another object, the object with a greater mass will suffer more severe damage. This is due to the demonstration and experiments carried out less emphasis on kinetic energy aspects. At the demonstration and experiment, the students observed and carried out their experiments to drop eggs with variations in size (or mass) and height imagined by students as demonstrations and potential energy experiments. The lack of emphasis that when it starts falling occurs the process of changing potential energy into kinetic energy makes students unable to imagine the influence of mass on kinetic energy. It also has an impact that students are unable to understand changes in mechanical energy in the case of energy conservation.

\section{Conclusion}

After learning is applied, students are tested again through the posttest. After going through the calculation process of the results of the posttest and pretest through the normalized gain, the gain in the moderate category was obtained $(<\mathrm{g}>=0.50)$. All students have understood the influence of the height 
Wijanarka et al.

of objects on the potential energy. 18 of them have understood the influence of the mass of objects on the potential energy. Students' understanding of the effect of object mass on kinetic energy has increased shown in the number 3 posttest learning gain score of 0.15 . Students' understanding of changes in the form of mechanical energy in falling objects also increases shown in the number 4 posttest learning gain score of 0.21 . Based on student's answers on posttest numbers 3 and 4 , it is known that the majority of students still unable to understand the effect of mass on kinetic energy and changes in the form of mechanical energy in falling objects.

Through the Wilcoxon signed-rank test, it was concluded that there were differences in the pretest and posttest learning outcomes, which means that there is an influence on the use of Interactive Lecture Demonstration methods on the learning outcomes of 7th-grade students in SMP Muhammadiyah 1 Mlati in 2018/2019 academic year on the conceptions of mechanical energy conservation.

\section{Reference}

[1] M. Y. Abdullah, "Strategi Efektif Pembelajaran Fisika: Ajarkan Konsep," Sriwijaya University, Palembang, 2012.

[2] D. Hestenes and M. Wells, "A mechanics baseline test," Phys. Teach., vol. 30, no. 3, pp. 159-166, Mar. 1992.

[3] D. Hestenes, M. Wells, and G. Swackhamer, "Force concept inventory," Phys. Teach., vol. 30, no. 3, pp. 141158, Mar. 1992.

[4] J. Clement, "Students' preconceptions in introductory mechanics," Am. J. Phys., vol. 50, no. 1, pp. 66-71, Jan. 1982.

[5] L. C. McDermott, "Millikan Lecture 1990: What we teach and what is learned-Closing the gap," Am. J. Phys., vol. 59, no. 4, pp. 301-315, Apr. 1991.

[6] S. Rachniyom, K. Toedtanya, and S. Wuttiprom, "Development of the Concept of Energy Conservation using Simple Experiments for Grade 10 Students," J. Phys. Conf. Ser., vol. 901, p. 012124, Sep. 2017.

[7] D. R. Sokoloff and R. K. Thornton, "Using interactive lecture demonstrations to create an active learning environment," Phys. Teach., vol. 35, no. 6, pp. 340-347, Sep. 1997.

[8] A. Mazzolini, S. Daniel, and T. Edwards, "Using interactive lecture demonstrations to improve conceptual understanding of resonance in an electronics course," Australas. J. Eng. Educ., vol. 18, no. 1, 2012.

[9] A. Mazzolini, T. Edwards, W. Rachinger, S. Nopparatjamjomras, and O. Shepherd, "The use of interactive lecture demonstrations to improve students' understanding of operational amplifiers in a tertiary introductory electronics course," Latin-American J. Phys. Educ., vol. 5, no. 1, pp. 147-153, 2011.

[10] J. J. Velarde, C. Alvarado, and A. Mijangos, "Evaluating an interactive lecture demonstration implementation in a lab setting: An example from a collisions and momentum learning activity," Lat. Am. J. Phys. Educ, vol. 6, no. Suppl. I, 2012.

[11] H. Georgiou and M. D. Sharma, "Does using active
Development of The Conception of Mechanical Energy Conservation with Interactive Lecture Demonstration...

learning in thermodynamics lectures improve students' conceptual understanding and learning experiences?," Eur. J. Phys., vol. 36, no. 1, p. 015020, Jan. 2015.

[12] M. Mukaramah, "Influence of the Drawing Media Through Computer to Learning Outcomes in Class X SMA Negeri 1 Bimomaru," Sci. J. Phys. Educ., vol. 4, no. 2, pp. 271$283,2015$.

[13] R. D. Suyanti, Strategi Pembelajaran Kimia. Yogyakarta: Graha Ilmu, 2010.

[14] R. R. Hake and J. . Reece, Analyzing change/gain scores. Indiana: Indiana University, 1999.

[15] Indarwati, "The Influence of Demonstration Image Analysis on Physics Learning and Knowledge of the Procedure of the Early Semester of Prospective Physics Teachers," Saintifika J., vol. 13, no. 2, pp. 1-15, 2015. 